\title{
Lean Production and World Class Manufacturing: A Comparative Study of the Two Most Important Production Strategies of Recent Times
}

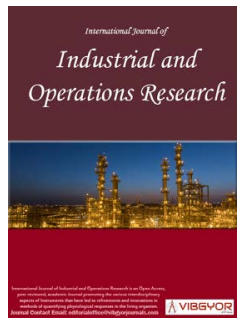

\section{Filippo De Carlo* and Gregorio Richardson Simioli}

Department of Industrial Engineering, University of Florence, Italy

\begin{abstract}
As a consequence of the rising competition in the markets and of the growing economic crisis that has affected most of the manufacturing industries worldwide, many companies have sought solutions to improve their productive performance. Because of this, Lean Production and World Class Manufacturing are the two most popular strategies which companies have tried to adopt with results that not always are most satisfactory. This Research Paper has the objective of identifying the reasons that may have caused the failure of these strategies, using analysis and comparison, to reveal their differences and the reasons why the full understanding of these differences is of fundamental importance in the choice between one or the other. The research period covered is that of the last 30 years (1986-2018) and the research can be classified as a systematic literature review, from a theoretical and qualitative point of view. The results of this paper show how, although the two manufacturing strategies share many common aspects, they do present some important differences, which can be attributed in some part to the different cultural context in which they developed. This paper also provides the tools for a better understanding of Lean and World Class Manufacturing literature and can be used as a useful support for further new research on these subjects.
\end{abstract}

\section{Keywords}

Lean manufacturing, World class manufacturing, Production strategy

\section{Introduction}

Considering the international economic crisis scenario, it has become important for the manufacturing industries to thoroughly rethink their production strategies, and to evaluate whether they are still adequate to satisfy the constantly rising demands of the international markets of the new millennium.

It is in this context that Lean Manufacturing and World Class Manufacturing (WCM) find their collocation. They represent two manufacturing strategies that have grown vastly during the last few years, and that have gained a constantly growing number of followers, made up of manufacturing companies that seek a solution to overcome productive difficulties and to be able to compete at high levels on the international market.

Before analysing the single strategies, it is important to focus on their historic background, to be able to fully appreciate the total revolution that industrial manufacturing has undergone in this period.

\footnotetext{
*Corresponding author: Filippo De Carlo, Department of Industrial Engineering, University of Florence, Italy Accepted: November 19, 2018; Published: November 21, 2018

Copyright: (C) 2018 Carlo FD, et al. This is an open-access article distributed under the terms of the Creative Commons Attribution License, which permits unrestricted use, distribution, and reproduction in any medium, provided the original author and source are credited.

Carlo and Simioli. Int J Ind Operations Res 2018, 1:001
} 


\section{Lean manufacturing}

Lean Manufacturing, only recently popular is a production philosophy based on the Toyota Production System, developed in Japan shortly after the end of World War II. The automotive industry of that period was dominated by American companies, in particular by Ford. These companies, as a consequence of Taylor's scientific work organization and Henry Ford's assembly line, were opening the way to mass production [1]. The vast amount of pieces produced, together with the repetitiveness and standardization of the production process had been the key to drastically reducing production costs, and launching on the market a product with prices affordable to the vast majority of the population [2]. In Japan the situation was totally different. As a means of helping to rebuild its economy, after World War II the Japanese government closed its borders to imports and destined a large percentage of its income (PIL) to the industrial sector of the market. This decision was fundamental for its economic growth during the following years, enabling the country to dedicate most of its resources to manufacturing activities [3]. It is in this economic context that Toyota emerged. Toyota's philosophy was in direct opposition to Ford's one. In fact, its general idea was that in a period of rapid growth, such as the one America was undergoing, a productive system based on quantity could be justified, but during a period of slow growth, like the one Japan was experiencing, it was best to concentrate more thoroughly on quality aspects.

To apply such a system, the only way was a deep and systematic elimination of all waste from the various manufacturing processes. Only then would it be possible, according to Taiichi Ohno (founder of the TPS model), to direct all the companies' resources to creating quality products at reasonable costs. During the following years Toyota was able to demonstrate the rightness of such a choice, by becoming in short time one of the principle automotive industries on national scale and receiving interest and attention from the industrial sector all over the country [3].

\section{World class manufacturing}

World Class Manufacturing originates towards the end of the 1980s in America, partly as a response to the achievements of Ohno's manufacturing model in Japan but did not gain success until the beginning of the twenty-first century, when it grew to become what it is today: a widespread production system adopted all over the globe. The terminology "world class" was first used by authors to refer to the capabilities developed by American and German companies to compete in international export markets [4], indicating an unmistakeable tendency to focus on prevailing on all competitors and aiming to become among the best in the manufacturing world.

The key idea behind the adoption of WCM is the pursuit of competitiveness on the part of firms that decide to adopt it, to gain a global status of excellence. As noted by Oliver, et al. [5], to qualify as world class, companies have to "demonstrate outstanding performance on measures of both productivity and quality", this underlines the competitive aspect of such strategy.

The research conducted in this paper has the objective of analysing the two models, in order to compare them and has been carried out following the methodology of a systematic literature review. The rest of the study is articulated as follows: To begin with, the methodology is described, through a thorough explanation of the research procedures. Next, a comparison is made between the two strategies, and the results are studied, so as to highlight the main differences found. The differences are then discussed and a possible cause for these differences is given. Finally, conclusions are made, and some possible future work is suggested.

\section{Methods}

The type of research conducted in this paper is to be considered theoretical research. The aim of a piece of Theoretical Research is, for its authors, that of expanding their knowledge and comprehension of the analysed phenomena. The path followed by this research is that of a qualitative systematic literature review. A Literature Review has the aim of summing up the "state of art" in the field of research considered. More specifically, a systematic literature review identifies and synthesizes the results of individual studies, following a rigid protocol, and thus represents a precious resource for information regarding the analysed topic. The adjective "qualitative" indicates that the process followed includes a synthesis and critique of the results obtained as a consequence of the application of systematic methods, but does not, however, combine, using statistic instruments, the results of all examined literature [6]. From the point of 


\section{Formulation of the research question}
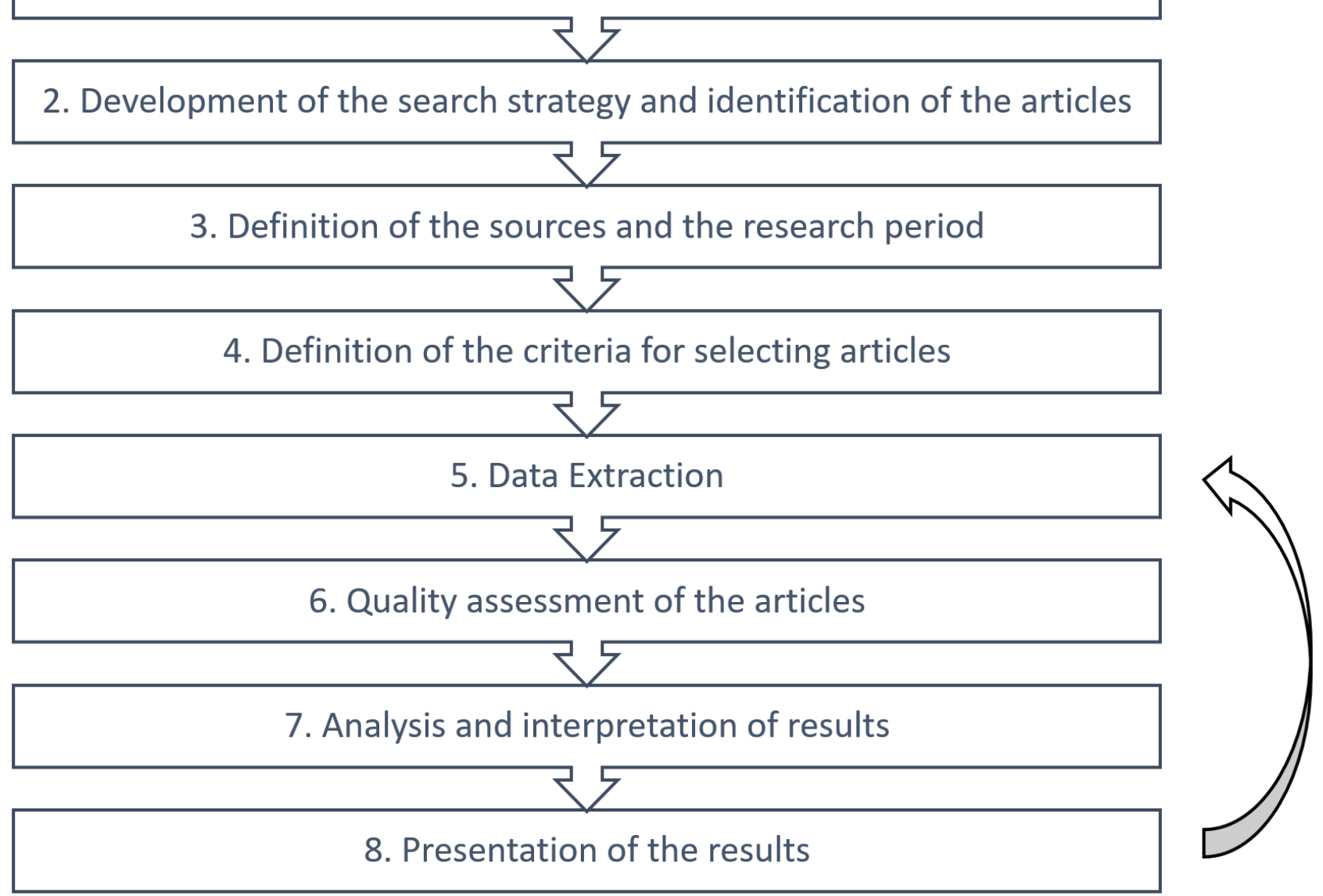

Figure 1: An ordered list of the steps that were followed to carry out the Systematic Literature Review. The arrows indicate the followed sequence. Once completed the eight steps, it is possible to repeat steps 5 to 8 in the case of further developments.

view of the objectives of the research, the present document can be considered a thematic review, that, according to the classification suggested by the Educational Research Review Journal, is a type of review that describes one or more specific literature areas, and that, through the definition of a central element of analysis and its evaluation from different points of view, gives a detailed analysis that helps answer a precise starting question [7]. The approach that the present research followed was of a qualitative, more than a quantitative, nature.

The sequence of the steps followed in conducting this research is shown in Figure 1. It is important to highlight how, once steps 1 to 4 have been specified and followed, the literary review may be repeated once again, also at different times, using the same criteria, to identify further data regarding the topic of study and to update existing data in the light of future developments.
The first step consisted in defining the objectives of the research, which allowed the formulation of the research question. In this case there was a double objective: to define Lean and World Class Manufacturing, together with some of their main characteristics, and to make a comparison between them, to identify the similarities and differences and to identify possible causes. The second step was that of developing a research strategy. Currently the most time and cost-effective way of conducting research is by consulting online databases. However, there is a huge quantity of information online, that is not always trustworthy or verified, and, most of all, not necessarily useful for the aim of the research. For this reason, the first phase of the research consisted exclusively of gathering documents from the vast literature databases. To do so, the main search engines used to find quality scientific articles were Google Scholar, Emerald, Science Direct, Springer, IEEE, 
Whiley and Taylor \& Francis, using keywords such as "Lean vs. WCM", "Comparison Lean WCM", "Lean and World Class Manufacturing strategies". Together with the articles found, various books concerning these topics were consulted, as tools to support and integrate the literature obtained from the online databases.

The third step consisted in an analysis and classification of the sources from which the academic literature was retrieved. Particular importance was given to the articles coming from the industrial area, leading to the exclusion of various articles addressing Lean and World Class from points of view not related to the topic of this research. It was decided to adopt a wide research period, due to the necessity of understanding the fundamental aspects of Lean and World Class Manufacturing, to be able to evaluate the evolution that the two strategies underwent during the past 30 years. For this reason, apart from special exceptions, all articles dating prior to 1986 were excluded.

The fourth step was a first analysis of the documents and articles collected, which lead to the exclusion of all those that weren't strictly connected to the research topic. The small number of articles left after this first filtration immediately uncovered the fact that in the academic literature there are very few articles that cover Lean and W.C. Manufacturing together, and that treat them from a comparative point of view. This finding underlined and validated the originality and usefulness of this research. It also pointed out the need for a further collection of articles from the online databases, which were obtained using this time the keywords "Lean Manufacturing", "World Class Manufacturing" and "Manufacturing Strategies" separately, and repeating steps 2 to 4 . After having obtained the final number of articles, these were divided and classified according to their date of publication. The results are shown in Figure 2.

The fifth step consisted in a more thorough analysis of the selected articles, together with a functional organization of the key aspects found in each article. In Figure 3 the type and quantity of the consulted documents are shown.

The sixth step saw the formulation of a classification system for the scientific journals and for the other sources from which the articles were recovered, to permit a qualitative evaluation of the research material. As regards the classification scheme, the model used was the "Scimago Journal \& Country Rank" (https://www.scimagojr.com/), a public website that classifies scientific journals according to their SJR indicator, "a numeric value indicating the average number of weighted citations received during a selected year per document published in that journal during the previous three years" (https://en.wikipedia.org/wiki/SCImago_

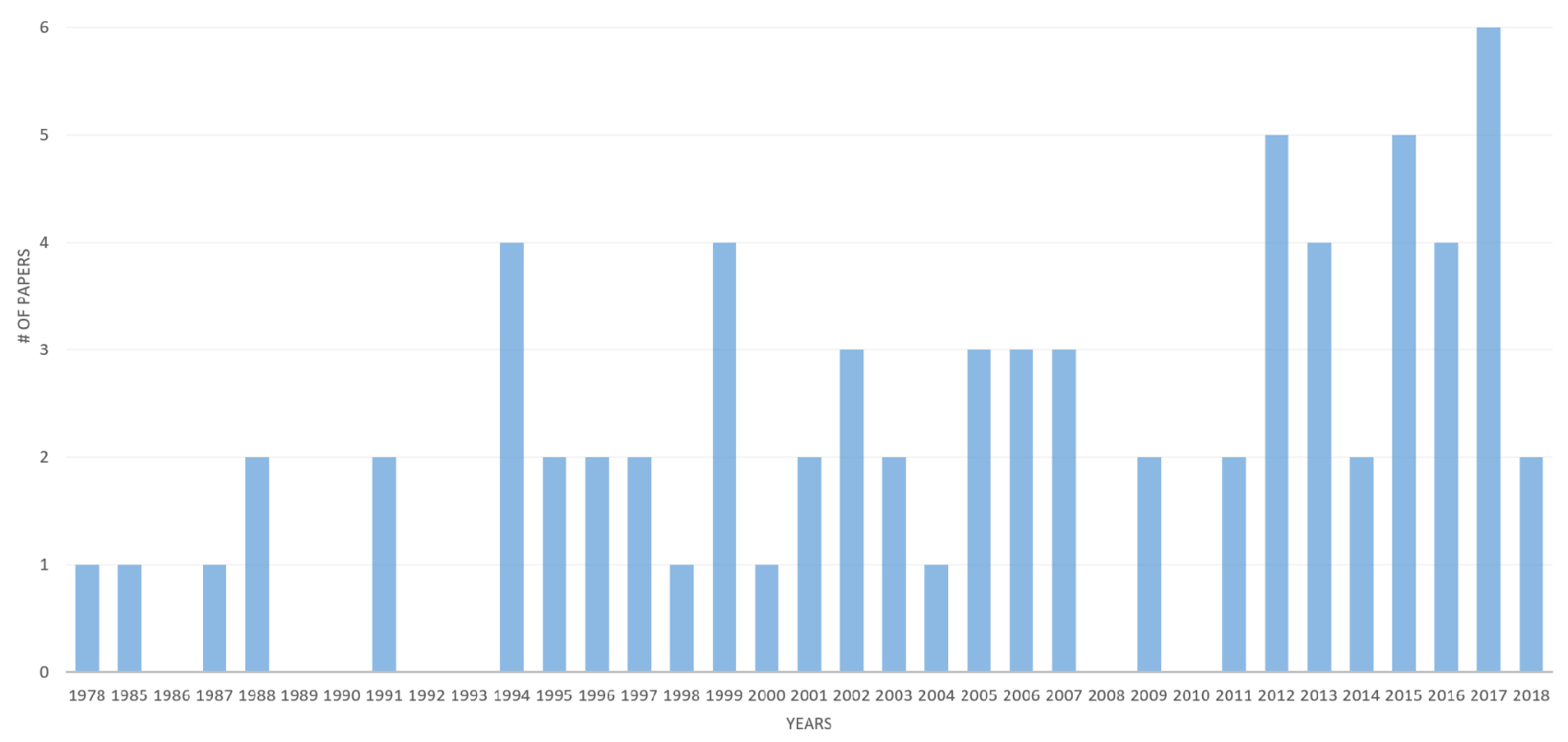

Figure 2: A Cartesian graph showing the quantity of articles selected per year. 


\section{Classification of the consulted documents}

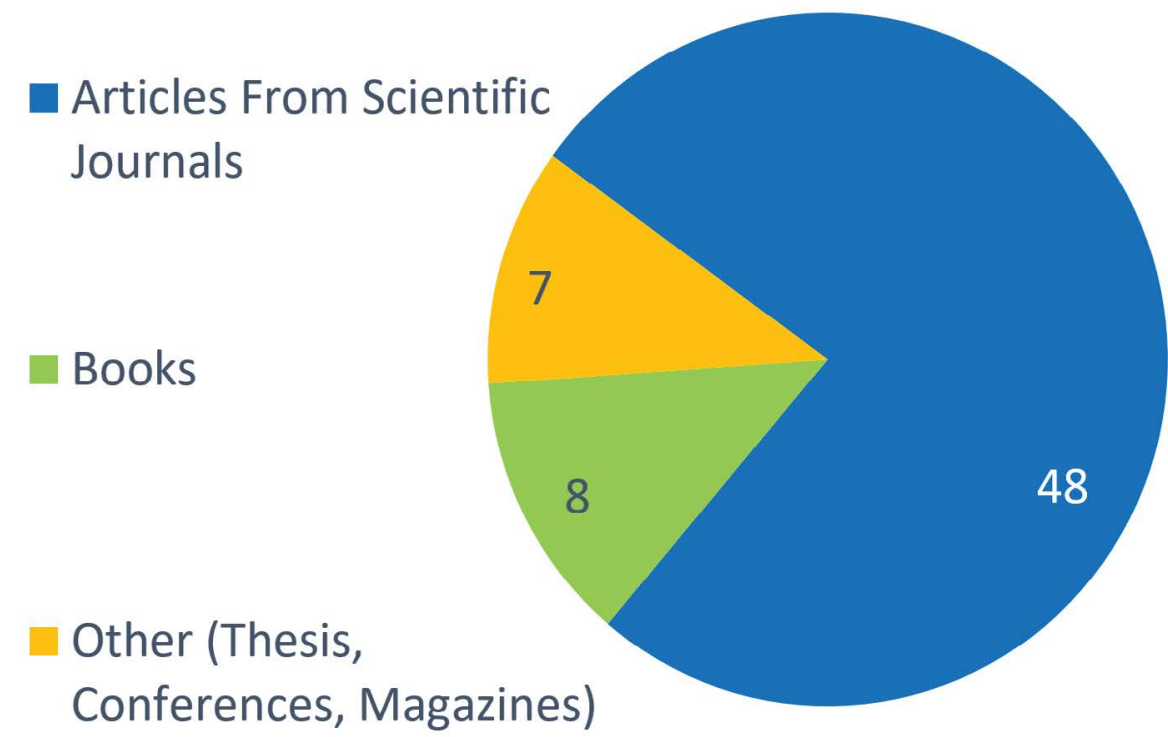

Figure 3: A pie-chart showing the quantity and type of the sources from which the data for the Literature Review was extracted.

Table 1: The table offers a classification of the Scientific Journals consulted, and an indication of the number of articles analysed from each journal. The indicators considered are: Q-Index, SJR-Index, the H-Index. Source: www. scimagojr.com.

\begin{tabular}{llllll}
\hline Journal & Quaterly index & SJR index & H-index & $\begin{array}{l}\text { Quantity of } \\
\text { articles }\end{array}$ \\
\hline Journal of economic literature & Q1 & 9,770 & 126 & 1 \\
\hline Strategic management journal & & & & \\
\hline Journal of operations management & Q1 & 6,278 & 199 & 1 \\
\hline Manufacturing and service operations management & Q1 & 5,052 & 134 & 5 \\
\hline Management science & Q1 & 4,609 & 57 & 1 \\
\hline Academy of management perspectives & Q1 & 4,384 & 181 & 2 \\
\hline IEEE Transaction on systems, man and cybernetics & Q1 & 4,258 & 88 & 1 \\
\hline International journal of operations \& production & Q1 & 3,921 & 124 & 1 \\
\hline management & & 2,198 & 94 & 9 \\
\hline International journal of production research & Q1 & & & \\
\hline British journal of management & Q1 & 1,445 & 91 & 5 \\
\hline Production planning and control & Q1 & 1,371 & 70 & 1 \\
\hline MIT sloan management review & Q1 & 1,295 & 50 & 2 \\
\hline Chemical engineering research and design & Q1 & 1,128 & 71 & 1 \\
\hline Business horizons & Q1 & 0,873 & 65 & 1 \\
\hline Total quality management and business excellence & Q1 & 0,726 & 51 & 1 \\
\hline Business process management journal & Q1 & 0,662 & 55 & 1 \\
\hline Journal of manufacturing technology management & Q1 & 0,614 & 42 & 1 \\
\hline International journal of quality and reliability management & Q2 & 0,605 & 45 & 3 \\
\hline Harvard business review & Q2 & 0,544 & 63 & 1 \\
\hline Quality progress & Q4 & 0,401 & 130 & 2 \\
\hline Quaderni storici & Q4 & 0,135 & 26 & 1 \\
\hline Journal of transportation technology & N/A & 0,100 & 6 & 1 \\
\hline
\end{tabular}




\begin{tabular}{|c|c|c|}
\hline \multicolumn{2}{|c|}{ International journal of engineering science and technology N/A } & 1 \\
\hline The TQM journal & N/A & 1 \\
\hline $\begin{array}{l}\text { International research journal of engineering and } \\
\text { technology }\end{array}$ & N/A & 1 \\
\hline Jurnalkejuruteraan (Journal of engineering) & N/A & 1 \\
\hline Zeszyty naukowe (Scientific journal) & N/A & 1 \\
\hline Books & N/A & 8 \\
\hline Other publications (Dissertations, conventions, papers) & N/A & 7 \\
\hline TOTAL & & 63 \\
\hline
\end{tabular}

\section{Quality of the articles from the Scientific Journals}

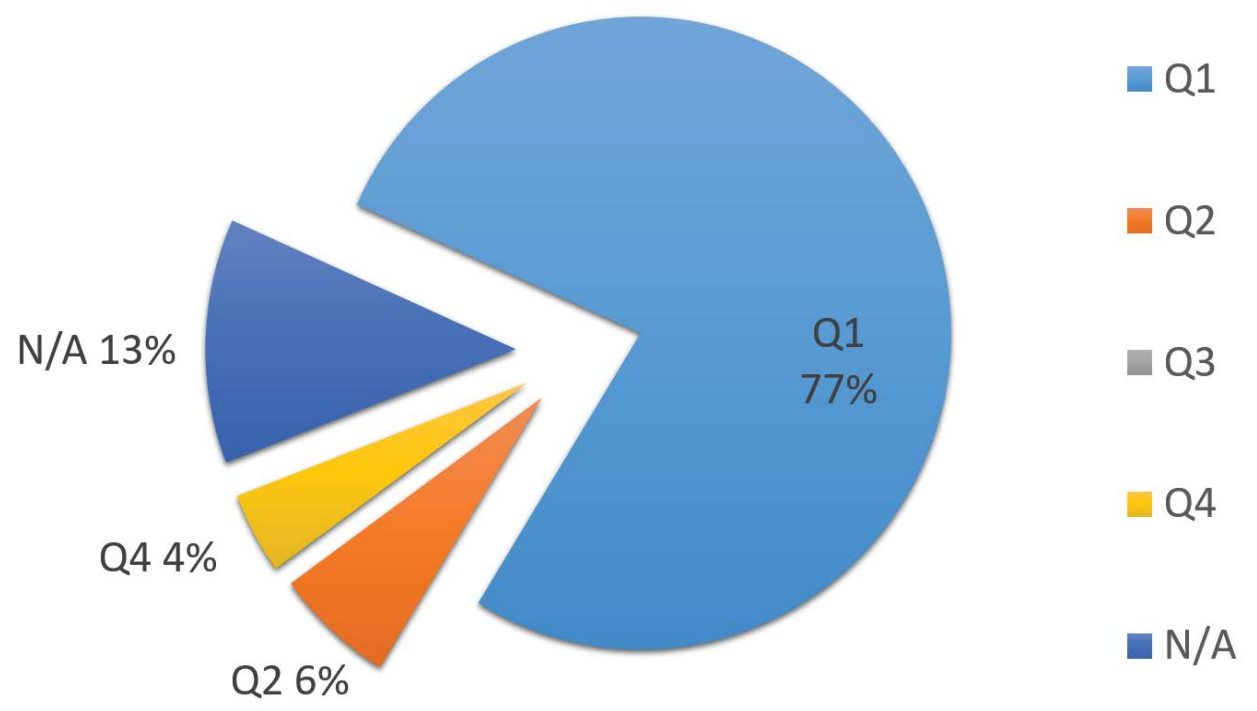

Figure 4: A pie-chart indicating quality of the selected articles on the basis of the Q-Index, an indicator that assigns each article a number from 1 to 4 (being 1 the top mark, and 4 the bottom one) according to the number of citations received in the scientific literature.

Journal_Rank). Such indicators are developed and calculated by Scimago using the Scopus database of peer-reviewed literature (https://www.scopus. $\mathrm{com} /$ ). The indicators taken into consideration were "SJR-index", "Q-index" and the "H-index", each of which gives the scientific journals a numerical value, proportional to the number of citations received in the scientific literature, which represent an important measure of their scientific influence. The results are presented in Table 1 and in Figure 4.

In the seventh step all data was processed and from it various convergent and divergent issues regarding the two manufacturing strategies were extracted. Possible motivations for these issues were studied.

The eighth and last step consisted in a presentation of the obtained results, in the form of short comparative paragraphs in which the various differences between the two models were brought up and listed in schematic tables.

\section{Results}

While reading the various scientific articles selected, it was noted that an actual comparison between the two strategies was hardly ever made, whereas in most of the literature considered, they were discussed singularly. However, what was found, was a tendency on the part of some authors, to assimilate the two strategies [8], often incorporating Lean Production as a part of World Class Manufacturing, and describing it, for example, as one of the best practices of which the WCM is composed [9]. Some authors merely indicate Lean Production as the system from which WCM stems [10-12] and of which it incorporates many elements [13] while others define World Class Manufacturing as a system that incorporates all the elements of Lean Production [14]. Finally, some authors state that WCM is simply a particular development of 
Table 2: The table contains a series of descriptions of the link between "Lean Manufacturing" and "World Class Manufacturing" according to a selection of authors who compare the two strategies in their articles.

\begin{tabular}{|l|l|}
\hline Authors & Relationship between Lean And WCM \\
\hline Sandeep e Panwar [9] & $\begin{array}{l}\text { Lean manufacturing is one of the best practices of the WCM, along with TQM, JIT, TPM, } \\
\text { Six Sigma. }\end{array}$ \\
\hline Cerruti [15] & $\begin{array}{l}\text { WCM is nothing more than a particular applicative development of traditional canons of } \\
\text { organizational Toyotism. }\end{array}$ \\
\hline Villano [12] & Lean production is the system fromwhich WCM originates. \\
\hline Silva, et al. [11] & $\begin{array}{l}\text { WCM is based on models created by the post-war Japanese manufacturing industry. It } \\
\text { adapts the new Lean ideas used by Japan to achieve significant competitive advantages. }\end{array}$ \\
\hline Leoni [16] & $\begin{array}{l}\text { WCM is the reference point, internationalized and industrialized, of the Lean production } \\
\text { model. It indicates a wide range of organizational elements of production that } \\
\text { characterize the companies that compete in the global market, but also incorporate the } \\
\text { concept of a dynamic organization in constant and rapid improvement. }\end{array}$ \\
\hline
\end{tabular}

Ab Rahman, et al. [8] During the development of Lean Manufacturing many terms were coined that refer to the same idea and model. including "WCM".

Murino, et al. [10] WCM is an integrated system that is based, among others, on the adoption of the Lean production principles and which is also used as a parameter to verify the actual state of implementation.

Naviglio [13] $\quad$ WCM incorporates the elements of Lean production, but the concept of "leanness" should be rethought, to be included in a larger pattern of strategic production.

Simoni [19] WCM companies must possess all the skills of Lean production, combined also with strategic aspects.

De Toni e Tonchia [14] WCM is in many respects similar to Lean production, with a focus on achieving World Class performance. When compared to Lean, WCM is also a little more "plump" losing in agility but gaining in Quality and Services.

the traditional organizational standards of Lean Production [15] and of which it represents an internationally institutionalized reference [16]. The thoughts of some of the analysed authors on the difference between Lean Production and World Class Manufacturing are summarized in Table 2.

This study has led to a general agreement with the views of most of these authors, confirming in principle a strong resemblance between the two models, but it has also found some aspects where the two production philosophies differ. Before describing these differences, a premise is needed: Lean Production and World Class Manufacturing are two dynamic production models, continually evolving, so what may be a feature of a certain WCM (or Lean) company will not necessarily be the same for all the companies. The aspects analysed in the following paragraph are therefore considered to be related not so much to the individual companies, but more to the theoretical aspects, widely recognized as characterizing the two theories.

\section{Basic structure and production strategy}

The biggest difference between the Lean model and the WCM one is certainly the strategic approach to production of the latter. As theorized by many authors [17-21] the main characteristic of WCM is that it represents a truly effective production strategy, which, if properly applied, is able to "push" the company towards global levels of excellence $[9,22]$.

The basic structure of World Class Manufacturing is based on the simultaneous adoption of TQM (Total Quality Management), TPM (Total Productive Maintenance) and JIT (Just In Time), which according to Yamashina [23] represent, in order, " [...] the brain, muscles and nervous system connecting them". It is then integrated with TIE (Total Industrial Engineering), a method developed in the '30s in the West, adopted by TPS and finally recovered by Yamashina [24], and with the pillars of Cost Deployment and Safety that connect them transversally [11].

Lean Production however, as claimed by some authors, such as Naviglio [13] and Simoni [19], does not have any explicit reference to a production strategy. The authors also discuss the lack, on the part of Lean, of a precise structure, since it is mainly composed of a set of tools and techniques, as 
claimed by Pavnaskar, et al. [25] (who also propose a functional classification of these instruments). Some authors, including Bhasin and Burcher [26], underline the fact that the only way for a Lean approach to production to be effective is if the company is able to consider Lean not just as "yet another productive strategy", but exclusively as an actual philosophy for the company to follow.

Another difference, from the point of view of the basic structure, is the lack of strategic emphasis shown by the Lean Production model. It pursues a path of improvement aimed mainly towards an individual development of the single company, reducing waste and achieving an efficient production [3,27]. Naviglio [13] argues that an intrinsic characteristic of the mentality of excellent production companies is their ability to think strategically. World Class Manufacturing, in the pursuit of a World Class status and the out-performance of the world's best companies, must have a strategic approach to production, as it is critical to its goals [18]. In any case, the implementation of WCM practices is a challenging task due to the combination of various tools, techniques used within the policies of the manufacturing company. These enablers must be managed carefully so that the company can achieve excellence in manufacturing and survive in a competitive environment [28].

\section{Model implementation and performance evaluation}

The verb "to implement" refers to the practical application of a method carried out in order to achieve a certain goal. As for Lean Production, given the lack of a single precise definition [29], it is impossible to specify an implementation path that may be considered universally valid. The existing implementation methods are based, therefore, on contingency, following common sense and the judgment of the business managers who engage in it [30].

In the scientific literature, various implementation systems have been suggested, each accompanied by its own evaluation method, but all with the common denominator of a de-contextualization from the actual reality of the individual company for which they were proposed. This reveals that the implementation process is strongly influenced, if not regulated, by the specific conditions of each company. Furthermore, the attempt to apply a universal process generates, in most cases, the oppo- site effect to that desired, leading to further waste rather than to improvements [30].

As for WCM in its original expression, authors such as Schonberger [18], Hayes and Wheelwright [31] describe the guidelines that a company should follow to pursue excellence, but they do not provide any indication with respect to an implementation methodology. The modern WCM, based on the model in use by Fiat Group spa, does not need an explicit deployment path, since such is already traced within the various steps that characterize its technical pillars [24].

The evaluation and achievement of performance levels, and therefore the implementation of a WCM evaluation model towards the World Class standards are carefully documented thanks to a complex system of audits [32]. These represent an important difference between the performance evaluation measures adopted by the two strategies. This system in fact, allows not only to have a real evaluation of the progress of the implementation model, but also provides feedback to workers about the effectiveness of their actions. In addition, and more importantly, it allows for continuous benchmarking of all the companies that adopt the WCM model, creating competition and resulting in positive steps in the path to excellence [24].

The majority of the authors, however, agrees on the need for a professional expert, the "change agent", who has already experienced the change, and who could be seen as a sponsor of the effective rightness of the model in the eyes of the workers. This professional figure would oversee the change process and counsel the company directors, particularly during the initial implementation of the new model $[24,27,33]$.

\section{Role of employees}

The role of the workers in a company has a very important part in both the Lean and the World Class models. Oliver, et al. [5], in the analysis of the factors that led to international success of the Lean model, analyse how work management is structured inside companies: it is based on teams and work groups, made up of flexible and multifunctional workers, who are also entrusted with roles of responsibility. Also Schonberger [18], in his first definition of the World Class model, states the need to look towards the Japanese model (especially the TPS, from which the Lean ideology was born), and suggests that it is necessary to modify the role of workers allowing 
them a greater participation in business processes (even though he limits his considerations to a very superficial level, without specifying the precise ways in which they should be involved).

De Toni and Tonchia [14] observe how in the Lean model the involvement of operators is possible by giving them the possibility to stop production whenever a defect presents itself (andon). By doing so they can face and solve the problem immediately with the help of all the other workers. This has contributed to create both a sense of responsibility and a versatility in the workers which has given them the opportunity to play a variety of different roles within the company. This concept is the same as that expressed by Hayes and Pisano [34], who point out that, in order to apply the Lean model in the West, it is necessary that workers receive a multifunctional type of training instead of a highly specialized one in a single sector.

Other authors, including Midor, et al. [32], point out that besides the educational aspect, it is essential to let employees understand the actual need for change and the modifications that will occur with the transition to the WCM model, so that they can contribute directly to the process of change.

What emerges from the analysed literature, is the theoretical need of a series of measures to promote the involvement, the motivation and the empowerment of workers, when a company wants to adopt WCM. These aspects, however, are not stressed so strongly within the Lean philosophy, since in Japan, where Lean originated, they are already a part of the national mentality.

This could be one of the reasons why there have been frequent cases of failure in the application of the Lean model to Western companies, as described by Cerruti [15]. Cerruti analyses how the model of the Integrated Factory, based on the Lean model and adopted by Fiat during the last decade of the past century, has not been very successful. He then attributes part of the blame for this failure to the different mentality of the western (mainly Italian) company staff in contrast to the Japanese one, due to an almost opposite cultural background. It is for this reason that in all the articles concerning the WCM model, the importance of a cultural change on the part of workers is strongly underlined: the workers, during the period of application of the new model, should receive rigorous training, on-site training and a system of input oriented incentives that encourage them to learn how to quickly understand the new mentality $[16,35]$.

A survey conducted in 2013 by the FIM (Federazione Italiana Metalmeccanici), has analysed the consequences that the introduction of the WCM in Fiat has had on the company. The results showed that, despite the fact that the survey was carried out more than six years after the introduction of WCM, the implementation path is still to be considered very long [15], given the considerable discrepancy between the various ways that such change was welcomed by the workers. Although many positive aspects were recognized as a result of the change (such as: higher quality, less waste, greater opportunity to contribute to business decisions), workers were sharply divided on other aspects (training system, working conditions, stressful timetables, the role of the team, inadequate system of rewards and feedback). This has led some authors to heavily criticize the new model, defining it as "a revival of the utopia of an ancient scientific managerial organization of work that, far from being set aside in the name of something else, is brought to its most radical, extreme consequences" [36]. Other authors quote Gorz [37], who stated that "it is no longer the individuals that operate as gears, but it has become the working team who does so".

Villano[12], finally, partlyagreeswith the previous authors, noting positively that the new production system based on WCM has introduced various aids to improve workplaces. Simultaneously, though, it has generated in the majority of workers a feeling of discomfort and stress due to the decrease in the quantity and duration of work breaks, considered now as a "non-value-adding" activity, By doing so it has also taken away from them the possibility to have important moments for an optimal recovery of their energy and strength, which reasonably will negatively affect their total productivity.

\section{Role of leadership}

As well as for employees, even the executive part of the company shows some differences between the two models. The first aspect concerns the method of implementation of the changes within the company: a lean executive, following the philosophy of genchi genbutsu, will adopt a "bottom up" approach, which consists in the pursuit of a choice by consensus, after taking into account all the opinions of the workers 
(considered to be of absolute validity, since they are the part of the company most in touch with the manufacturing processes), and after having studied closely the production process. This aspect is treated by many authors, including Gollhar, et al. [38] and Alukal [39], who show that the key roles of Lean leaders are and have been: the search for consensus, the "motivating" of the work force, the adoption of an age-based wage system that also takes into consideration the experience gained in the company, the paternalistic and respectful approach towards workers, an effective communication strategy and a fixed position that will last throughout their lifetime. Although some of these concepts are no longer applicable in modern industries, they played an important role in the initial development of the Lean philosophy. The authors also argue that, in order to adopt the Lean techniques (in particular referring to "Just in Time") in Western companies, an "employee orientated" approach is necessary, on behalf of the executives.

As a result of this approach, Hayes and Pisano [34] observe how in Lean companies there is a reduction of the hierarchies, and a change in the communication strategy between management and workforce, that now takes place in an informal and horizontal fashion. This aspect is, together with what has been seen previously, a further reason for the failure of the Lean "Integrated Factory" of Fiat [15]. The application of Lean-to Fiat led to a sharp contrast between the actual model and the method of implementation, having been undertaken following a "top down" approach, typical of a mentality still strongly attached to the hierarchical structure of the company, through a series of impositions by senior management who demonstrated a lack of full understanding of the Lean Production model. The "modern" model of the WCM (which evolved with a strong contribution on the part of Fiat), formalises the role that the company executives should have, instituting 10 Managerial Pillars that give a great importance to elements such as planning, leadership, motivation and organization that, on the contrary, had not been institutionalised in the Lean model $[9,24]$.

The theme of the reduction of hierarchies is also considered in the article by Diodato Pirone [35], who describes an incident which occurred during the inauguration of a new Fiat-Chrysler factory in 2013 in Indiana. The episode itself, a sentimental embrace between Fiat's CEO Marchionne and a representative of the workers, is nothing unusual; what instead is to be noted is how such an episode represents an example of an overcoming of the traditional hierarchical structure. During the inauguration, the distance between workers and leaders presupposed by the hierarchical structure disappears, leaving the two men standing next to each other as equals. The author notices, in fact, how with the application of WCM, Fiat has become a company with a flat, personal structure obtaining benefits in terms of information sharing and decisional speed. This fact is further evidenced by the abolition of the distinction between "blue collars" and "white collars" in the company (workers and managers now both wear a normal grey suit), and by the shift of the administrative offices to a new position, just a few steps away from the production line, demonstrating a change of mentality, now much closer to the original Japanese one which is at the base of Lean Production [33].

\section{Quality and value}

In his original definition of World Class Manufacturing, Wheelwright [40] states the importance of distinguishing between "real quality" and "perceived quality". He adds that it is necessary to choose whether to define it as the absence of defects, or in terms of performance capabilities, noting that one of the two will necessarily always have to be sacrificed (acknowledging the existence of trade-offs). In the following decade, thanks to the rise of Lean in the western world, Hayes and Pisano [34] demonstrate how the previously described dualism has been overcome by integrating the best practices from the Lean model to the WCM model. Both in the Lean model and in the WCM model quality is considered from the perspective of the end user, and the production goal becomes customer satisfaction [33].

A concept that still has to be defined in most Western companies is that quality should be an intrinsic part of the product and should not require a subsequent verification because it should already be ensured by all the operations that created the product. This conception is a particular characteristic of the Lean model, for which the downstream controls play the role of "non-valueadded activities", and as such, according to Taiichi Ohno, represent waste [3]. On the other hand, for WCM companies, the application of the Quality Control Pillar must enable them to follow the 
example offered by Lean and adopt a prior control system rather than a subsequent verification [24].

Value, in Lean companies, plays a central role, and requires, as stated by Womack and Jones [27], a mapping of its flow, to identify the set of all the operations that contribute to its growth. The instrument with which the Lean model performs this mapping is Value Stream Mapping (VSM). The central role of VSM, within the Lean Production, is highlighted by the role of the "Value Stream Manager"; management takes place by processes, and the starting point is always the "Value Analysis" [33]. It is not possible to say the same for the WCM companies, in which this instrument is hardly used, overshadowed by the Pillar logic, and in which the identification of non-value added activities takes place through the Cost Deployment Pillar [24].

\section{TPM, TQC, TIE and JIT}

These four elements, respectively, Total Productive Maintenance, Total Quality Control, Total Industrial Engineering and Just-in-time, represent the four methods of which the World Class Manufacturing model is composed, in its most modern definition $[9,24,41]$. These methods, also present in Lean Manufacturing, are taken into the WCM model where they are integrated in a strategic context focused on excellence $[16,32]$. The most important of these is certainly Total Productive Maintenance, which has as its objective an increase in production volume and worker satisfaction, through a proactive and effective approach in terms of costs towards the maintenance of production equipment [42]. It is not a conventional maintenance practice, but more like a philosophy, incorporating a whole series of other practices, such as Autonomous Maintenance, Early Equipment, Concurrent Engineering and Quality Maintenance, that it has assimilated in its path of continuous evolution, from the $30 \mathrm{~s}$ when it was invented, to the present day [23]. The formalization of these four methods, in the World Class Manufacturing model, under the form of Technical and Managerial Pillars is the main difference respect to Lean Production, where the most emphasis is placed on Just In Time [3,27,43].

Just like many of the differences listed so far, it is observed that almost all are attributable to a more rigorous definition of WCM, as compared to the Lean model. The latter as previously described, does not present a single definition and is generally identified as a set of tools and techniques [44].

\section{Safety}

A big novelty theorized by WCM is represented by the importance that is given to safety in the workplace, most probably because of the increasing proliferation of European rules and regulations regarding such issue. Safety is to be intended as the situation in which every worker is placed in the best possible work conditions without exposing them to the risk of accidents or injuries [24]. This concept is analysed, among others, also by Arsovski, Dokić, \& Pesic-Dokic [45], who emphasize that it is crucial for a company to be responsible for the safety of its employees. The fact that Safety represents the first of the WCM Technical Pillars, confirms how it has a central role in the guidelines of a WCM company and how it should necessarily also be at the base of all the other pillars. This is confirmed by the results of a survey carried out by Chiarini, et al. [41], in a Fiat factory, through a series of questionnaires and interviews with 13 directors of the factory. The results showed how Safety, along with Quality, are considered part of the foundations of the policies of a company, without which it isn't possible to apply any other Pillar. The survey also brought to light the fact that within Fiat, in the Lean period before the implementation of the WCM model, safety was not considered a priority. This aspect is in accordance with the original Japanese model, in which there were no explicit references to workplace safety [10].

\section{Discussion}

Despite the fact that they may seem, in many ways, to be two identical approaches to production, LM and WCM show several factors that distinguish them. Table 3 gives a summary of the results obtained during the study, highlighting the main differences identified between them.

Focusing on Quality, for example, it is clear from sections (c), (e) (f) and (n) that it is a characteristic deeply eradicated in the WCM approach to production, being it both one of the main pillars that support it and a direct consequence of one of the main targets ("zero defects"). It must be pursued by all components of the company as testified by the built-in system of performance indicators that assure a centralized control of all parts of the production process. In Lean Manufacturing, on the contrary, Quality is seen as a natural consequence of a correctly programmed and carried out production process. A possible downstream Quality Control 
Table 3: The table summarises the main differences identified between Lean and World Class (Adopted and extended from Ab Rahman, et al. 2012 [8]; Bolwijn \& Brinkman, 1987 [48]).

\begin{tabular}{|c|c|c|c|}
\hline & Category & Lean approach & World class approach \\
\hline (a) & Basic structure & Not present & $\begin{array}{l}10 \text { technical pillars and } 10 \text { managerial pillars; } \\
\text { each technical pillar consists of a further } 7 \text { steps }\end{array}$ \\
\hline (b) & Production strategy & $\begin{array}{l}\text { No reference to an explicit } \\
\text { production strategy }\end{array}$ & Cost deployment \\
\hline (c) & Quality control & $\begin{array}{l}\text { No downstream control, as it } \\
\text { would be considered aNon- } \\
\text { Value Adding Activity (NVAA) }\end{array}$ & $\begin{array}{l}\text { Its one of the technical pillars, that seeks to } \\
\text { obtain "zero defects" }\end{array}$ \\
\hline (d) & Strategic emphasis & $\begin{array}{l}\text { Continuous improvement } \\
\text { in personal development } \\
\text { perspective, and as a tool for } \\
\text { reducing waste }\end{array}$ & $\begin{array}{l}\text { Every action and business decision must be } \\
\text { aimed at achieving global excellence }\end{array}$ \\
\hline (e) & Performance evaluation & $\begin{array}{l}\text { No universally recognized } \\
\text { model. Whilst the many models } \\
\text { proposed in literature are } \\
\text { based solely on productivity } \\
\text { and efficiency assessments }\end{array}$ & $\begin{array}{l}\text { Complex and structured Auditing system } \\
\text { (internal and external) with recognition by } \\
\text { the WCM association who assign awards of } \\
\text { merit }\end{array}$ \\
\hline (f) & Performance measurement & $\begin{array}{l}\text { Limited number of KPI (Key } \\
\text { Performance Indicators), } \\
\text { measurements made very } \\
\text { often, with results shared } \\
\text { with the rest of the company } \\
\text { through a visual control system }\end{array}$ & $\begin{array}{l}\text { High number of KPI, but with a centralized } \\
\text { control system of the measured parameters }\end{array}$ \\
\hline (g) & Safety & $\begin{array}{l}\text { No explicit reference in the } \\
\text { original Japanese model }\end{array}$ & $\begin{array}{l}\text { Occupies an essential role, as evidenced by } \\
\text { the fact of it being indicated as the first pillar }\end{array}$ \\
\hline (h) & Benefits-to-costs ratio & $\begin{array}{l}\text { Not considered. All the wastes } \\
\text { are equally treated and tackled } \\
\text { regardless of their influence on } \\
\text { the costs }\end{array}$ & $\begin{array}{l}\text { Logic of economic rationality in the choice of } \\
\text { the priorities. Benefits-to-costs ratio treated } \\
\text { as the first indication resulting from cost } \\
\text { deployment }\end{array}$ \\
\hline (i) & Identification of losses & Value stream mapping & Cost deployment \\
\hline (j) & Implementation of change & "Bottom up" approach & $\begin{array}{l}\text { "Bottom up" approach, taken by following } \\
\text { the } 10 \text { pillars }\end{array}$ \\
\hline (k) & Justification of change & A priori & Frequently neglected \\
\hline (I) & $\begin{array}{l}\text { Leadership, planning, } \\
\text { motivation and organization }\end{array}$ & Not explicitly discussed & $\begin{array}{l}\text { Discussed in a systematic way in the } \\
\text { managerial pillars }\end{array}$ \\
\hline (m) & Implementation & There is no universal method & Managerial pillars \\
\hline (n) & Target & $\begin{array}{l}\text { Drastic reduction of waste, } \\
\text { creation and flow of value }\end{array}$ & $\begin{array}{l}\text { Zero waste, zero defects, zero stocks, zero } \\
\text { failures }\end{array}$ \\
\hline (o) & TPM & Focus on people and processes & Focus on equipment \\
\hline
\end{tabular}

would instead be a form of waste. According to Lean Manufacturing, Quality must necessarily be built in directly to every product right from the beginning.

From the point of view of Safety, it is possible to appreciate from sections (a), (g) and (n) of Table 3 , that it is an issue that has great importance in the World Class Manufacturing philosophy, that has led it to become the first of its 10 technical pillars and to have a dedicated "road-map" indicating how to implement it in the company [46]. Occhipinti, et al. [47] argue that one of the reasons of such importance is the fact that companies are realizing that most of the injuries that occur on the workplace are a consequence of an incorrect and unregulated behaviour on part of the workers and link such opinion to the concept of culture and mentality of the workers. The Lean Manufacturing approach to safety, conversely, is practically not existent, or at the very least does not find an explicit reference in the original Japanese model, so imaginably it is left to the discretion of each single company. 
Considering Costs, sections (b), (h), (i) and (n) of Table 3 indicate how they represent the core of WCM's production strategy, that is applied via the Cost Deployment pillar. WCM companies can correctly identify and classify all costs associated with each form of waste and with its removal, following their main target of "zero waste". After their classification, costs are tackled following a rigorous logic: the first improvements to be made are those that maximise the benefits-to-cost ratio. Such logic does not exist in Lean Manufacturing where every form of waste is treated equally, and has equal removal priority, regardless of the impact it has on the global costs of the company. Instead of focusing on costs, Lean Manufacturing concentrates its efforts more on the identification and enhancement of Value, by using VSM methods.

Many of the differences seen so far can be attributed to cultural differences between the East (especially Japan) and the West (especially America and Europe), where the two models were developed respectively. These differences should not be considered negatively, but rather they must be observed as a positive element that the models have absorbed from the context in which they were born.

The Lean Production model, based on the Japanese Toyota Production System, has a strong introspective character, and entrusts the task of carrying out the improvement of the company to the employees, relying on the strong tendency of the individuals to identify themselves with the group to which they belong.

The WCM model, however, inspired by Western culture, has a markedly individualistic character; at the same time, however, it has a strong competitive spirit that channels its application towards the desire to excel globally. However, the staff, to be able to work together to achieve this goal, need a strong set of rules and motivations, to force them to put aside their personal interests and pursue the interests of the company.

Further evidence confirming this thesis is given by the failure of the application of the Lean model to a European context such as that of Fiat, as noted by Cerruti [15], who describes how the application was carried out without adopting the proper change of mentality needed in order for it to be effective. The traditional Fordist culture present in the West (and in this particular case, in Italy) in the early 90 s, led to, in the case of Fiat, a "top down" and "expertocratic" application of the Lean Production model, which resulted in an incomplete application. In fact, it was not sufficient simply to implement the necessary Lean Tools, such as Just In Time, Kanban, levelled production (and many others) to obtain an improved performance of the company; on the contrary, the lack of the right culture [26] led to, in subsequent years (inevitably characterized by waste and inefficiency) a great uncertainty at management level and a strong sense of uneasiness that moved the company away from the key points of the Lean Philosophy, namely: continuous improvement, development of staff skills, comparison between objectives and results. It also brought to light all the problems that inevitably led to the crisis of the company, and to what was ironically called the "drifted integrated factory". The extent to which this failure is to be attributed to the different mentality of Fiat workers respect to Japanese industry workers is objectively difficult to quantify, but it is the authors' belief that the cultural aspect cannot be neglected, being it the starting point for an industrial culture to be built.

In Table 4, adapted from the work of Bolwijn and Brinkman [48], some aspects of Japanese culture are schematically reported and compared to Western culture. It is easy to notice immediately how many of the differences between Lean Production and World Class Manufacturing could be somehow related to cultural differences between the two contexts in which they originated.

\section{Conclusions and Future Work}

The objective of this study was to investigate in detail two of the most important industrial production strategies of recent times that play a leading role in the industrial landscape of the present and will surely do so also in that of the nearfuture. Subsequently, based on the collected data, it was decided to try to bring out the common and diverse aspects of the two strategies and to create a list of features that distinguish them. Finally, by analysing the differences found, an attempt was made to identify a common factor between them, that was identified in the different cultural, social and industrial context in which the two strategies were created and developed.

The research carried out, given the continuous and constant evolution of manufacturing is intended to 
Table 4: In this Table various aspects of the eastern and of the western cultures are compared, in relation respectively to Lean and World Class Manufacturing (Adopted and extended from Ab Rahman, et al. 2012 [8]; Bolwijn \& Brinkman, 1987 [48]). In bold are highlighted the cultural aspects that can be retrieved in the two production strategies. On the left side arrows indicating the directions of growth of the social and management dimensions are shown.

\begin{tabular}{|c|c|c|}
\hline Category & Japan & Western world \\
\hline $\begin{array}{l}\text { Relation with } \\
\text { nature }\end{array}$ & Adaptation to the outside world & Comparison and competition with the outside worlo \\
\hline Religion & $\begin{array}{l}\text { Buddhism and Shinto, which have the } \\
\text { objective of avoiding worries and concerns }\end{array}$ & $\begin{array}{l}\text { Christianity, which preaches absolute moral values, } \\
\text { the salvation of the soul and has a strong emphasis } \\
\text { on the good/evil dualism }\end{array}$ \\
\hline Lifestyle & How to live & What to live for \\
\hline Focus on & The present and tangible & Future and abstract \\
\hline Life philosophy & Man makes his path great & God makes great man great \\
\hline Society & Built on direct personal relationships & Built on contractual relations with legal character \\
\hline Orientation & Orientation to the group; Group selfishness & Orientation to the individual \\
\hline $\begin{array}{l}\text { Individual } \\
\text { behaviour }\end{array}$ & Governed by adaptation to the group & $\begin{array}{l}\text { Regulated by a system of rules, punishments and } \\
\text { rewards }\end{array}$ \\
\hline Social relations & $\begin{array}{l}\text { Importance of frame groups, such as: } \\
\text { company, neighbourhood, nation }\end{array}$ & $\begin{array}{l}\text { Importance of the attribution groups, such as family } \\
\text { and social class }\end{array}$ \\
\hline $\begin{array}{l}\text { Social } \\
\text { structure }\end{array}$ & $\begin{array}{l}\text { Strong hierarchical structure and personal } \\
\text { relationships }\end{array}$ & $\begin{array}{l}\text { Weak hierarchical structure, and contract-based } \\
\text { relationships }\end{array}$ \\
\hline $\begin{array}{l}\text { Personal } \\
\text { relationships }\end{array}$ & Based on mutual obligations and trust & Based on rights and duties \\
\hline $\begin{array}{l}\text { Personal } \\
\text { formation }\end{array}$ & $\begin{array}{l}\text { Aimed at cooperation and mutual } \\
\text { dependence }\end{array}$ & Aimed at personal development and independence \\
\hline \multirow[t]{6}{*}{$\begin{array}{l}\text { Role of } \\
\text { workers }\end{array}$} & $\begin{array}{l}\text { Private life and corporate life are closely } \\
\text { related }\end{array}$ & $\begin{array}{l}\text { Clear separation between the company and its } \\
\text { employees }\end{array}$ \\
\hline & $\begin{array}{l}\text { Devotion and dependence towards the } \\
\text { company }\end{array}$ & Spirit of independence \\
\hline & Important role rotation & Little rotation \\
\hline & Active participation and indoctrination & Passive and indirect participation \\
\hline & Competition between groups/Teams & Competition between individuals \\
\hline & $\begin{array}{l}\text { Little difference between different company } \\
\text { departments }\end{array}$ & Clean cut between different company departments \\
\hline \multirow[t]{6}{*}{ Company } & $\begin{array}{l}\text { Little classification and formalization of the } \\
\text { departments }\end{array}$ & Well-defined and classified departments \\
\hline & Need for coordination & Need for self-assertion \\
\hline & $\begin{array}{l}\text { Higher emphasis on the role, more than on } \\
\text { the function inside the company }\end{array}$ & $\begin{array}{l}\text { Role and function inside the company are the same } \\
\text { thing }\end{array}$ \\
\hline & $\begin{array}{l}\text { The production line workers participate in } \\
\text { the operational decisions }\end{array}$ & $\begin{array}{l}\text { The production line workers have little or no } \\
\text { participation in the operational decisions }\end{array}$ \\
\hline & $\begin{array}{l}\text { Many groups and interdisciplinary project } \\
\text { teams, oriented towards problem solving }\end{array}$ & Very few groups and teams \\
\hline & Paternalistic role dedicated to supervision & Authoritarian role dedicated to surveillance \\
\hline \multirow[t]{4}{*}{ Management } & Decisions taken collectively & Individual decisions \\
\hline & $\begin{array}{l}\text { Two-way communication between } \\
\text { management and workers }\end{array}$ & $\begin{array}{l}\text { Poor communication between management and } \\
\text { workers, or at most unidirectional }\end{array}$ \\
\hline & $\begin{array}{l}\text { Cooperation between management and } \\
\text { workers in order to achieve the objectives. } \\
\text { Little difference in social status }\end{array}$ & $\begin{array}{l}\text { Contrast between management and workers and } \\
\text { huge difference in social status }\end{array}$ \\
\hline & Results attributed to the Group & Results attributed to individuals \\
\hline
\end{tabular}


Evaluation of In the recognition of the merits of the results

leader, his group's performance is important

Age and length of service play an important role in the salary and promotion system High percentage of the salary depends on the performance of the company
In recognition of the merits of the leader, the role of his group is scarcely considered

Age and durations of the service do not have much weight in the salary and promotion system Almost no relationship between salary and performance of the company

be a starting point for researchers and professionals who wish to consider a possible application of one of the two models to a specific case.

Possible future developments of the work may include, but are not necessarily limited to:

- Investigations on what could be the most appropriate model to apply to different types of companies;

- Studies of the possibility of overcoming the differences described in this paper and of creating a new, hybrid, model;

- Surveys aimed at determining if and how the two models can be applied to sectors other than the industrial one.

\section{References}

1. Batchelor R (1994) Henry Ford, mass production, modernism, and design. Manchester University Press.

2. Alizon F, Shooter SB, Simpson TW (2009) Henry Ford and the model $\mathrm{T}$ : Lessons for product platforming and mass customization. Design Studies 30: 588-605.

3. Ohno T (1978) Toyota production system-aiming at an off-scale management. Diamond Co, Tokyo, Japan.

4. Harrison A (1998) Manufacturing strategy and the concept of world class manufacturing. International Journal of Operations \& Production Management 18: 397-408.

5. Oliver N, Delbridge R, Jones D, Lowe J (1994) WCM. Further evidence in lean production debate. British Journal of Management 5: S53-S63.

6. Green BN, Johnson CD, Adams A (2001) Writing narrative literature reviews for peer-reviewed journals: Secrets of the trade. Journal of sports chiropractic and rehabilitation 15: 5-19.

7. Jesson J, Matheson L, Lacey FM (2011) Doing your literature review: Traditional and systematic techniques. Sage.

8. Ab Rahman MN, Ho CK, Jamian R, Ramli NF, Cherng NM (2012) Comparative study of manufacturing strategy between Japanese and Western approaches:
An Overview. Jurnal Kejuruteraan 24: 35-43.

9. Sandeep, Rajesh KA, Panwar N (2016) World Class Manufacturing (WCM) practices: An introspection. International Research Journal of Engineering and Technology 3: 2359-2362.

10. Murino $T$, Naviglio $G$, Romano E, Guerra L, Revetria $R$, et al. (2012) A world class manufacturing implementation model. Applied mathematics in electrical and computer engineering 371-376.

11. Silva LCS, Kovaleski JL, Gaia S, Garcia M, Júnior PP de A (2013) Cost deployment tool for technological innovation of world class manufacturing. Journal of Transportation Technologies 3: 17-23.

12. Villano $V$ (2015) The WCM as a management optimization tool. The Lear corporation case (PhD Thesis). Università degli studi di Pisa.

13. Naviglio G (2011) Policies for controlling production of the pull type. Comparative analysis through a simulative approach. (PhD Thesis). University of Naples Federico II.

14. De Toni A, Tonchia S (2002) New production models: A strategic view. International Journal of Production Research 40: 4721-4741.

15. Cerruti GC (2015) World class manufacturing at FIAT and the social and organizational dualisms of lean manufacturing. Economia \& lavoro 49: 37-54.

16. Leoni R (2013) World-class manufacturing and productivity. Handbook in Economic Organization, Cheltenham: Edward Elgar.

17. Miller JG, Roth AV (1994) A taxonomy of manufacturing strategies. Management Science 40: 285-304.

18. Schonberger R (1986) World class manufacturing: The lessons of simplicity applied. Free Press, New York, USA.

19. Simoni C (2002) Strategic approach to production: Beyond lean production. Firenze University Press.

20. Sweeney MT (1991) Towards a unified theory of strategic manufacturing management. International Journal of Operations \& Production Management 11: 6-22. 
21. Wheelwright SC, Clark KB (1988) Dynamic manufacturing: Creating the learning organization. Simon and Schuster.

22. Petrillo A, Felice FD, Zomparelli F (2018) Performance measurement for world-class manufacturing: A model for the Italian automotive industry. Total Quality Management \& Business Excellence.

23. Yamashina H (2000) Challenge to world-class manufacturing. International Journal of Quality \& Reliability Management 17: 132-143.

24. Pela F (2016) Analisi del world class manufacturing. il caso FCA. Recuperato da.

25. Pavnaskar SJ, Gershenson JK, Jambekar AB (2003) Classification scheme for lean manufacturing tools. International Journal of Production Research 41: 3075-3090.

26. Bhasin S, Burcher P (2006) Lean viewed as a philosophy. Journal of Manufacturing Technology Management 17: 56-72.

27. Womack JP, Jones DT (1996) Lean thinking: Banish waste and create wealth in your corporation. Free Press, New York.

28. Ekta, Saha R (2017) World class manufacturing: A review. International Journal of Engineering Technology Science and Research 4: 625-630.

29. Pettersen J (2009) Defining lean production: Some conceptual and practical issues. The TQM Journal 21: 127-142.

30. Karim A, Arif-Uz-Zaman K (2013) A methodology for effective implementation of lean strategies and its performance evaluation in manufacturing organizations. Business Process Management Journal 19: 169-196.

31. Hayes RH, Wheelwright SC (1984) Restoring our competitive edge: Competing through manufacturing.

32. Midor K (2012) World class manufacturing-characteristcs and implementation in an automotive enterprise. Zeszyty Naukowe/Akademia Morska w Szczecinie 32: 42-47.

33. Liker JK (2005) The Toyota way. Esensi.

34. Hayes RH, Pisano GP (1994) Beyond_world-class: The new manufacturing strategy. Harvard Business Review.
35. Diodato Pirone (2014) Fiat Chrysler, un modello anomalo (2014). Mulino, (Fascicolo 4).

36. Leonardi S (2015) Wcm at Fiat: What implications for working conditions and industrial relations. Quaderni di Rassegna Sindacale-Lavori 2: 131-142.

37. Gorz A (2010) Critique of economic reason. Verso Trade.

38. Golharr DY, Stamm CL (1991) The Just in time philosophy: A literature review. International Journal of Production Research 29: 657-676.

39. Alukal G (2003) Create a lean, mean machine. Quality Progress 36: 29-36.

40. Wheelwright SC (1984) Manufacturing strategy: Defining the missing link. Strategic management journal 5: 77-91.

41. Chiarini A, Vagnoni E (2015) World-class manufacturing by Fiat. Comparison with toyota production system from a strategic management, management accounting, operations management and performance measurement dimension. International Journal of Production Research 53: 590-606.

42. Prabhuswamy MS, Nagesh P, Ravikumar KP (2013) Statistical analysis and reliability estimation of total productive maintenance. The IUP Journal of Operations Management 12: 7-20.

43. Wakamatsu Y (2009) The Toyota mindset, The ten commandments of Taiichi Ohno. Enna Products Corporation, Bellingham, WA.

44. Bicheno J (2004) The new lean toolbox. Buckingham: Picsie Books.

45. ArsovskiS, Dokićl, Pesic-Dokic S (2013) Quality in world class manufacturing. Presentato al $6^{\text {th }}$ International Quality Conference, Center for Quality, Faculty of Engineering, University of Kragujevac. Recuperato da.

46. Mercadante L, Terracina A, Spada G (2014) La World class manufacturing: Strumenti e metodi per migliorare la salute e la sicurezza dei lavoratori. 389-394.

47. Occhipinti S, Marandola V, Brun A (2014) World class manufacturing: An integrated framework to achieve excellence in safety. PoliMI. Recuperato da.

48. Bolwijn P, Brinkman S (1987) Japanese manufacturing: Strategy and practice. Long Range Planning 20: 25-34. 